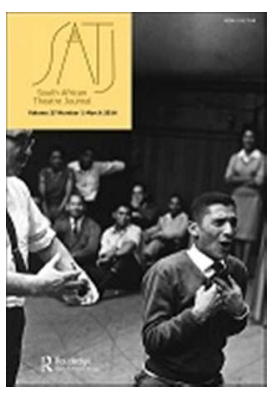

\title{
Living the Experience of Learning: Embodied Reflexivity as Pedagogical Process
}

\begin{tabular}{|r|l|}
\hline Journal: & South African Theatre Journal \\
\hline Manuscript ID & RTHJ-2017-0035.R2 \\
\hline Manuscript Type: & Original Paper \\
\hline Keywords: & $\begin{array}{l}\text { Embodied knowing, reflexive practice, theatre games, storytelling, } \\
\text { reciprocity }\end{array}$ \\
\hline \multicolumn{2}{|l}{} \\
\hline
\end{tabular}

\section{SCHOLARONE"}

Manuscripts 


\section{Living the Experience of Learning: Embodied Reflexivity as Pedagogical Process}

\section{Introduction}

As theatre practitioners we constantly 'do', acting, speaking and moving. But where does this 'doing' coming from? How might we develop an approach to pedagogy that recognizes the primacy of relationships $s_{2}$ and the braiding of language ${ }_{2}$ and the shifting emotional states that are associated with characteristics of our behaviour? How do we live and experience these relationships in a way that enables learning processes to occur both for ourselves and those we teach? These are the questions that we explore in this paper, using our experiences and research to identify how embodied learning ("which arises through the bodily, lived experience of the practitioner and is revealed in action" [Kinsella 2007, p. 396]) enables us to develop pedagogical processes to support theatre practitioners in learning how to learn.

Judith Pippen with Dianne Eden (1997) explored the implications of this understanding of | embodiment for voice and movement training for actors. TheirHer approach is based in the "dynamic inter-relationship of our bodyhood and its multidimensional relational space"

| (Pippen, p. 72), where we work together. Thisspace overcomes body/mind splits in human relationships and our relation to the world we are in. It does this "because it postulates the dynamic of our bodyhood-in-relation as generative of both moving and languaging, rather than

| movement belonging to the body and voice as somehow separated from it" (p. 72).

Furthermore, "the more emotional, kinaesthetic, imaginative and conceptual maps of the territory, the more that can be sensed, the more discerned, and the richer the potential for intense relationships which are the 'stuff' of theatre" (90). Understanding how we embody the spaces we are in - temporal, aesthetic, geographic -creates an emerging question:

How aware are we as theatre pedagogues of the ways we respond verbally and kinaesthetically to what happens around us in the classroom or workshop space?

Developing this awareness is connected to the way in which we as facilitators view our practice; in other words, how do we reflect and 'reflex' on what we do? Modern concepts of reflection and reflective practice have their roots in relatively recent work carried out by theorists and practitioners involved in the development of education and training in the 1980s, predominantly for those in the caring professions (social work, health care, education) with the main exponent at that time being Donald Schön (1983). Having gained prominence in the field of management learning, and against a growing tide of managerialism and accountability which began in the 1980s, reflection became thought of by many as a tool to measure performance rather than to develop the self. In the last four decades, there have also been a myriad of terms being generated to describe reflection in some form; critical reflection, reflexivity, critical learning, experiential learning, transformational learning, action learning (Fook,2 2010). 
However, the origination of reflection as a concept came from a desire to enable individuals to generate new knowledge about their own specific experiences. Creating criticality in reflection enables individuals to take the concept of reflection to a deeper level ${ }^{1}$. Rather than just have their actions reflected to them as a mirror would show back what is there, critical reflection asks questions about the reflection which hat can enable greater opportunity for transformational learning experiences (Linds and Vettraino, 2 22015):= This resonates with Mezirow who regards reflection as a mental process requiring higher order cognitive reasoning (Mezirow 1991) with the ability to learn from previous experiences in order to move beyond as being vital in developing an individual. Like Fook (2010), Mezirow (1991) makes a distinction between reflection and a deeper and spiralling form of critical reflection which he terms reflexivity. Reflexivity is the art and action of bending back (Steier 1991) in the moment of action to create deeper, transformational learning. This form of thoughtful action involves the idea of the transformative 'stop' moment (Applebaum 1995); the ability to halt the action and think about what is working and not working in order to affect change, much like Boal's (1995) metaxis.

This leads to a central focus for this article on what kind of lens and practice would help theatre teachers and facilitatorsethers learn reflective, reflexive and mindful awareness that empowers them to access their intuitive and embodied abilities and fuels their interpretive and imaginative powers in their theatre pedagogy practice. In this article, we create the context for the paper through discussion of a framework used to support our own reflection and the work of theatre practitioners. In particular, we use a framework drawn from Canadian Indigenous pedagogy called the 4Rs (Kirkness and Barnhardt, 1991) as a tool to analyse our own practice and outline the norms we are trying to enact in for this particular piece of work. Secondly, wWe alseuse the 4 Rs framework in this context as a tool to support the capacity for critical reflection on how we respond aesthetically. Moving forward, two particular contextual examples are used; one from Canada and one from Scotland. In the exploration of these contexts, we examine how the 4Rs framework might be adapted to support facilitator/teacher awareness of their kinaesthetic responses to situations in their practice. We conclude by suggesting that the 4Rs framework, linked to theories of embodied cognition, isare useful in reflecting on practice.

In particular we use the framework of the 4R's (Kirkness and Barnhardt, 1991) as an analytical framework that outlines the norms for our work.

\section{The 4Rs}

The 4Rs (relevance, responsibility, respect and reciprocity) were identified by Kirkness and Barnhardt(1991) as key value principles in welcoming and hosting Canadian First Nations and Native American (Indigenous) ${ }^{2}$ students in higher education. They write that normally the under-representation of these students in higher education is attributed to factors such as attrition, lack of academic achievement, lacking resilience, thus blaming the problem on the 
student. The 4Rs suggest a different set of values and since the original article these principles have been applied to Indigenous pedagogy and Indigenous research. For example, the Canadian Institutes of Health Research - Aboriginal Peoples Health position on Aboriginal Knowledge translation (KT) (Estey, Smylie and Macaulay, 22 2009) note that the 4Rs "are embedded in [KT] guidelines" (para 4). So Wwe have taken the 4Rs as representing some best practices in theatre workshop facilitation and, in turn, looked at how they serve help-us as a framework which provides norms we try to attain inwerk in our individual contexts for this article.

From the perspective of the Indigenous student these principles emphasize the need for a higher educational system that respects them for who they are, relevant to their view of the world, offers reciprocity in their relationships with others, and that helps them exercise responsibility over their own lives (emphasis added) (p. 1). Drawing from this perspective, these values $\underline{\underline{T h e} 4}$ Rs help us understand key values that can be applied to relationships with-participants in any context, enabling and enable themparticipants to experience through their bodies in relationship with each other what those values might look and feel like in practice-.- - Author 2, in his work, has added the core principle of relationality which binds both the experiential and the theoretical, contesting the compartmentalization of knowledge and requiring embodied relationships with individuals and communities. In her work on storytelling for embodied reflexivity, Author 1 uses the 4Rs to frame exploration of narrative as a container for lived experiences. Like Author 2, Author 1 has added relationality as a $5^{\text {th }} \mathrm{R}$ linking the learning from the work discussed to her own experiences and then on to further possibilities.

From the perspective of the Indigenous student the issue of engaging in higher education is often cast in more human terms, with an emphasis on the need for a higher educational system that respects them for who they are, that is relevant to their view of the world, that offers reciprocity in their relationships with others, and that helps them exercise responsibility over their own lives (emphasis added) (p. 1).

These relationships emerge through sharing authority. Sharing authority means being relevant, respectful, responsible, and engageing in pedagogy where all are teachers and learners, and all exchangeboth teacher and learners exchange knowledge in a process of co-creation, with shared decision-making about, and ownership of, the learning process, including the content that emerges and how we make sense of it.

Shared authority occurs when the facilitator recognizes participants' histories and uses her or his authority to bring their knowledge, and thus their authority of knowing, to the learning. In this way, authority emerges in dialogical relationships between facilitator and participant. Such a dialogical relationship must also be embodied as relationality itself emerges in interaction. (Linds, Goulet and Sammel 2013). 
Embodying the 4 Rs in theatre pedagogy

One way we have come to understand the 4 Rsisto frame themas being dynamicalways in motion and embodied. To experience what these mean, Author 2 has explored these aspects in embodied ways through theatre games.

The theatre director Tadashi Suzuki underlines an important aspect of kinaesthetic learning:

Any time an actor thinks he is merely exercising or training his muscles, he is cheating himself. These are acting disciplines. Every instant of every discipline, the actor must be expressing the emotion of some situation, according to his own bodily interpretation. (Brandon 1978, p. 36).

For Suzuki's actors, training such as games and exercises exist to "make the whole body speak, even when one keeps silent" (Zarilli 1995, p. 78-79). For Suzuki, 'the body' becomes the primary metaphor for the optimal state of the actor in performance. We, the authors, would extend this notion to include theatre educators and facilitators who, after all, use their bodies in their work. In this way, be Becoming aware of what we tacitly know happens through embodied activities. The exercises that both Authors use are traditionally (see, for example, Rohd,1998) called warm-up games that create trust and energy and develop teamwork. They are seen, therefore, as part of theatrical exploration. However, in the context of an inquiry process into the 4Rs, what emergeshappens if we explore such kinaesthetic-based approaches are evident as part of the knowing that emerges in theatrical work and thustherefore can inform every level of the creative process rather than just remaining at the level of simple warm-up games?

The theatre director Tadashi Suzuki underlines the point:

Any time an actor thinks he is merely exercising or training his muscles, he is cheating himself: These are acting disciplines. Every instant of every discipline, the actor must be expressing the emotion of some situation, according to his own bodily interpretation. That's why I don't call them exercises or physical fitness teachers don't go on stage. We do (Brandon, 1978, p. 36).

For Suzuki's actors, training such as games and exercises exist to "make the whole body speak, even when one keeps silent" (Zarilli, 1995, p. 78 79). For Suzuki, 'the body' becomes the primary metaphor for the optimal state of the actor in performance. We, the authors, would extend this notion to include theatre educators and facilitators who, after all, use their bodies in their work.

\section{What does this look like?}

Augusto Boal (2002) underlines that: 
in the body's battle with the world, the senses suffer. And we start to feel little of what we touch, to listen to very little of what we hear and to see very little of what we look at .... In order for the body to send out and receive all possible messages, it has to be reharmonised. ( $p$. 49).

The body "is not an object, but a grouping of constantly changing lived--through meanings" (Linds, 2 2006, p. 114) that are innate, acquired, and dependent on culture and history. The application of this shifting and changing is explored in the two examples we will outline in this article.

In order to further explain the link between the 4Rs and embodied pedagogy, we will outline the worldview on embodied cognition that underpins our work.

In order to situate our approach to embodied pedagogy, we will first of all outline a worldview about embodied cognition that underpins our work.

\section{Embodied Cognition}

According to Francisco Varela, Evan Thompson and Eleanor Rosch (1991), cognition does not happen in the mind of the perceiver, but rather between the perceiver and the world he/she inhabits. The perceiver does not live independently (in a vacuum) and construct meaning about the world, since "what counts as a relevant world is inseparable from the structure of the perceiver" (p. 13). We know the world because our bodies interact with/in the world through the structure permitted by our senses that co-evolved with the world. In this enactive view, "cognition has no ultimate foundation or ground beyond its history of embodiment" (p. xx).

Varela et al. refer to that awareness which is not attached to any one body, event, or concept as | "groundlessness" (1991; p. 144). If knowing is understood as anchored, it is anchored within the unfolding of events and is perpetually adrift in the movement of relationships. Groundlessness welcomes the unexpected. Whenever we find ourselves holding tightly to being in a certain place, or seek to control outcomes, we are invited to step into "another domain where coexistence takes place" (Maturana and Varela 1992), a both/and, rather than an either/or space. New possibilities emerge for action and knowing.

Inspired by the Buddhist philosophy of a middle way (a non-dualistic approach which proposes codependence between self and world), Varela et al propose such a path of being-in- the-world in which we drift in the knowing space between ourselves and world (including others), and are open to change and motivated by compassion. As contrasted with a worldview that locates knowing in minds, and knowledge as a relatively fixed and permanent commodity, an enactive 
approach engages us in experiencing the everyday world with more than a desire to ground, objectify, fix, and reify. Thus, knowing is revealed in common sense, that is "knowing how to negotiate our way through a world that is not fixed and pre-given but that is continually shaped by the types of actions in which we engage" (Varela et al 1991, p. 144). The value of this living cognition consists in being able to select, within broad constraints, the relevant issues that need to be addressed at a given moment. What is relevant to a particular moment is contextually determined by the sense of what is needed and not needed. To call attention to the reciprocal and dialogical relationships in which organism and environment, self and other are intertwined in a living system, Varela et al. call this process of cognition through everyday experience coemergence.

\section{Living systems}

Living systems are structurally coupled by recurrent interaction (Fell, Russell and Stewart 1994). As Maturana (1987) writes,

| If I have a living system ... then this living system is in a medium with which it-interacts. Its dynamics of state result in interactions with the medium, and the dynamics of state within the medium result in interactions with the living system. What happens in interaction? Since this is a structure determined system ... the medium triggers a change of state in the system, and the system triggers a change of state in the medium. What change of state? One of those which is permitted by the structure of the system (p. 75).

This process and these relationships constitute knowledge and cognition which Varela et al. elaborate further as involving embodied action whereby "sensory and motor processes, | perception and action are fundamentally inseparable" (1991; p. 172-173). Varela et al. exemplify this notion of experiential and enacted cognition through a discussion of colour ( $\mathrm{p}$. 157-171). Claiming colours are neither out there independent of our perception and knowing, nor are they 'inside us' independent of the world, Varela et al. see cognition encompassing both - colour is both experienced and belongs to the world in which we live. This middle path resolves the classic inner versus outer, mind versus body debate by looking at knowledge not as representation but as embodied enaction emerging in structurally coupled relationships.

An example of structural coupling in the realm of biological cognition is illustrated by this metaphor:

$-$

To draw a carp, Chinese masters warn, it is not enough to know the animal's morphology, study its anatomy or understand the physiological functions of its existence. They tell us that it is also necessary to consider the reed against which the carp brushes each morning while seeking its nourishment, the oblong stone behind which it conceals itself, and the rippling of water when it springs toward the surface. These elements should in no way be treated as the fish's environment, the mileu in which it evolves or the natural backgroundagainst which it can be 
drawn. They belong to the carp itself...The carp must be apprehended as a certain power to affect and be affected by the world (Feher and Kwinter 1986, p. 10).

In other words, "enaction is the idea that organisms create their own experience through their actions" (Hutchins 2014, p. 428).Understanding oneself in this way is to sense the space of possibility as being constantly co-enacted and re-enacted in our encounters. Embodied action is also not purely about the self, the individual learning from experiences around them; it is also about understanding the influence actions, thoughts, words have on others. This conscious requirement for embodied reflexivity is echoed in the work of Alvesson et al. (2008) who discuss the nature of embodied reflexivity within research processes. Exploring their practice as reflexive researchers, they argue for an understanding of embodied reflexivity that engages relationally the subjects and researchers in an evolving process. Embodied reflexivity is therefore about being wholly conscious of one's own feelings and emotions in order to be fully immersed in the here and now (Finlay,2 2005; XXXX 2 2008; Varela et al., 1991). It is about acknowledging that no one just observes, an observer is impacted on ${ }_{2}$ and impacts, the actions taking place (Halling and Goldfarb; 1991).

What are the consequences for theatre pedagogy of such an approach to cognition?

Leigh and Bailey (2013) discuss embodied reflection as 'living and lived experience.' Having self-awareness, a conscious understanding of one's own thought processes during an experience and being able to reflect through connecting with how one's body has reacted is embodied action. There is clearly a strong correlation between embodied reflection within the field of reflective practice and embodiment as part of the work of arts (and other) therapies (Jennings, 1998, 22012; Jones, 22007; Leigh and Bailey, 2013). In therapeutic theatre or drama work (as opposed to Dramatherapy practice), theatrical processes enable spaces for embodied reflection to occur as the reflective cycle in the drama practitioner is a constant and often unconscious process, arising through their need to engage bodily with character and role; theirs and others (Beirneand Knight, 2 2007).

The embodied nature of the learning arrived at through reflection cannot be emphasized enough because all thought is a consequence of reflection upon embodied nervous activity which, through its further interaction with the nervous system, becomes an object of additional nervous activity. "All doing is knowing; all knowing is doing" (Maturana and Varela 1992, p. 27). Reflection thus emerges through the bodily, lived experience of the person and is revealed in action. Essentially, knowing emerges in doing. In other words, we work reflexively through our bodies; what Finlay (2005) terms "corporeal reflexivity" (p. 272) in order to move forward in 
our understanding of the world around us and also of ourselves.

Maturana and Varela argue that, through the process of reflection upon experience, we define moment by moment - our changing world. Explanation through language then takes that | definition into a_social domain, creating another context for both experience and reflection because language is not a representation of a world 'out there,' "but rather as an ongoing bringing forth of a world through the process of living itself” (Maturana and Varela 1992, p. 11). For example, as facilitators or teachers, we engage in discourse with creators and tellers or stories, and also with listenersin engaging in a discourse with a listener in the process of storytelling, we 'bend back' (the literal meaning of the etymological root of reflexive) our reflexive self-stories and dig underneath to create new pathways and new critical learning for both ourselves as storytellers and the listener.

The arts connect the expression of self to communication with others. Boal (1992) wrote about this connectivity saying "we cannot live in isolation, under arrest inside ourselves....we can learn from each other: we are different, being the same" (p. 2). Yet the relationships that exist in | ateaching are not equal and learning in these contexts is not an autonomous act. In the creation of new knowledge, there are power dynamics and through understanding the impact of context on the individual, facilitators have to be aware of the possibilities of changing the power | dynamic and therefore affecting transformational change (Fook and Gardner,2 2007). There is authority, sometimes shared, but always there. For example, Author 2 has used interactive theatre techniques where, as participants create images from their lived experiences, the facilitators respond to those images and use them to further create other, more composite or social, images that tell universal stories. As the participants create more images, the facilitators respond to their creations again, in an iterative spiral of creation and response between participants and facilitator, with authority shifting from facilitator to participant and back again.

Stacey and Griffin (2005) point out that we cannot distinguish the individual and social as separate from one another. "The individual is the singular and the social as the plural of interdependent embodied persons.....Individuals are paradoxically forming and being formed by the social at the same time" (emphasis in the original, p. 32-33). One approach is to think of the pedagogue 'occasioning' (Davis, Sumara and Luce-Kapler 2000) change. Occasion comes from a Latin term used to describe how possibilities arise when things are allowed to fall together. Used as a verb, to occasion something is to bring something about, but not always deliberately, through changing the conditions of interaction. An occasioned event is one that may be incidental or by chance. These rich and diverse possibilities are always present in the act of pedagogy. However, the idea of having a flexible and diverse response to key events that unfold in any space means having a responsiveness that is faithful to goals, but that also allows for adaptability to the dynamism of 'real time' learning (Davis, Sumara and Luce-Kapler). This fits with Stacey and Griffin's (2005) experience of looking at when transformative processes occur 
in groups.. They use a complexity framework in working with groups and writes that we can't change people or the pattern of their interactions, but we can change the conditions in which people interact:

It is not possible for committed groups of people to intentionally change the widespread pattern of their interaction. All they can change is their own interactions, and from this widespread | patterning will emerge in ways they cannot intendt or fully understand....As people make sense differently, they act differently, and it is in this action, in continuing interaction with others that macro patterns change in emergent ways which cannot be predicted or controlled (p. 33).

It is this emergent process that is important in play. Here wich involves the participants are continuously adapting actions to new circumstances. where-Oepportunities are offeredereated to create together in a 'safe enough space' different from day-to-day school life, an 'as-if' world where the imagination can emerge. Both participants and facilitators are free to make mistakes or to fail and to learn.

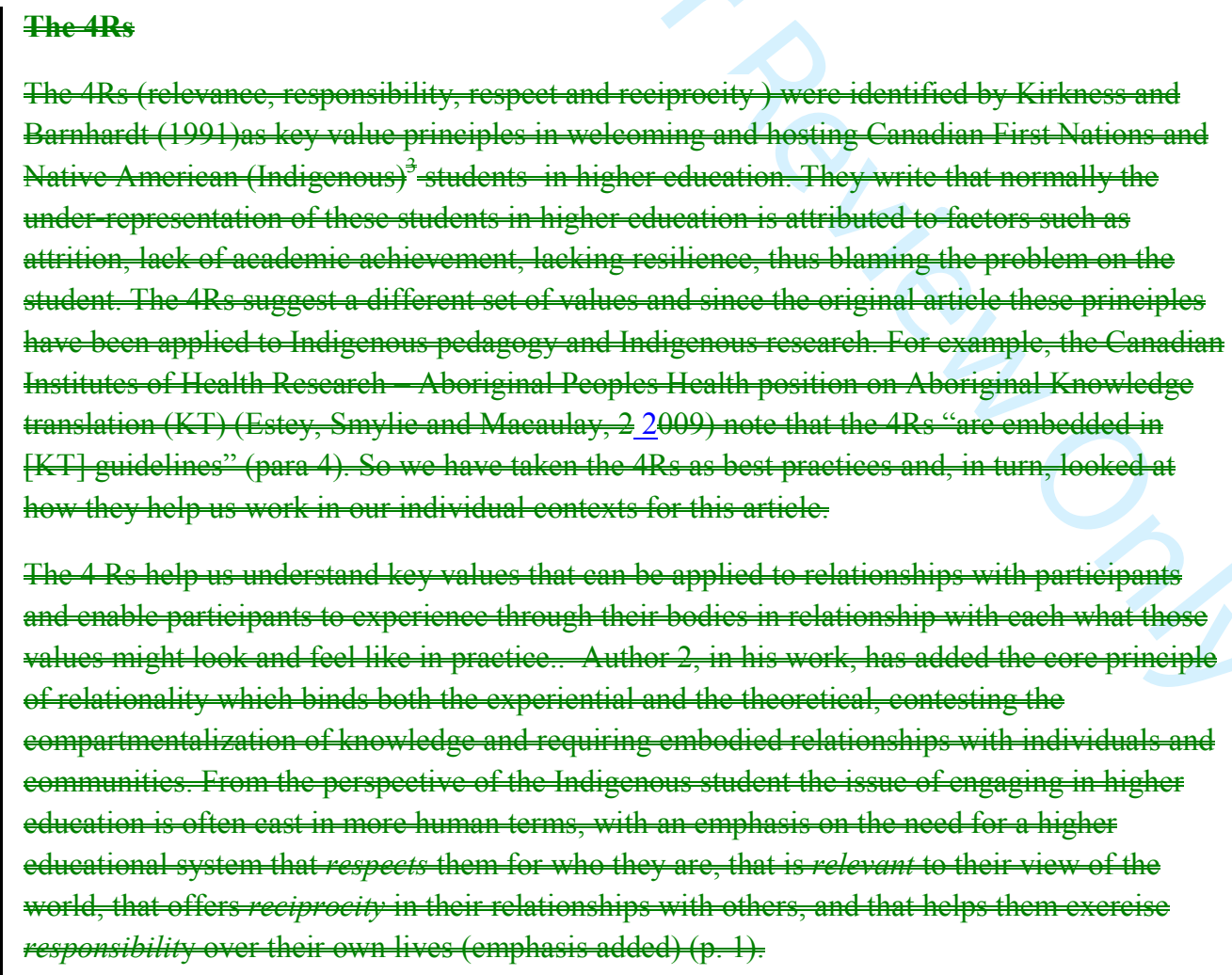


These relationships emerge through sharing authority. Sharing authority means being relevant, respectul, responsible, and engage in pedagogy where both teacher and learners exchange knowledge, with shared decision-making about and ownership of the learning process, including the content that emerges and how we make sense of it.

Shared atthority oceurs when the facilitator recognizes participants' histories and uses her of his authority bring heir kn this way, authority emerges in dialogieal relationships be fueen failitator and participant. Suleh a dialogieal relationship must also be embodied as relationality itself emerges in interaction. (Einds, Goulet and Samme1 2013).

\section{Embodying the $4 \mathrm{Rs}$ in theatre pedagogy}

One way to understand the $4 \mathrm{Rs}$ is to frame them as always in motion and embodied. To experience what these mean, Author 2 has explored these aspects in embodied ways through theatre games.

Becoming aware of what we tacitly know happens through embodied activities. The exercises that both Authors use are traditionally (see, for example, Rohd, 1998) ealled warm-up games that reate and energy and develop thwork. They are seen, therefore, as pat theatrieal exploration. However, in the context of an inquiry process into the $4 \mathrm{R}$, what happens if sueh kinasthetic based approaches are evident as part of the knowing that emerges in theatrieal work

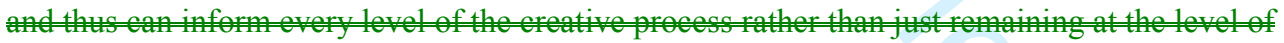
simple warm-up games.

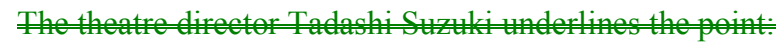

Any time an a thinks he is merely exercing training his muscles, he is chenting himself These are acting disciplines. Every instant of every discipline, the actor must be expressing the emotion of some situation, acording to his own bodily interpretation. That's why I don't call them exercises or physical fitness teachers don't go on stage. We do (Brandon, 1978, p. 36).

For Suzuki's ators, training such as games and exereises exist to "make the whole body speak, en kilent" (Zarilli, 1995, p.78 79). For Suzui, 'the dy' bemes the primary metaphor for the optimal state of the actor in performance. We, the authors, would extend this notion to include theatre dueators and facilitators who, after all, use their bodies in their ork.

\section{What does this look like?}




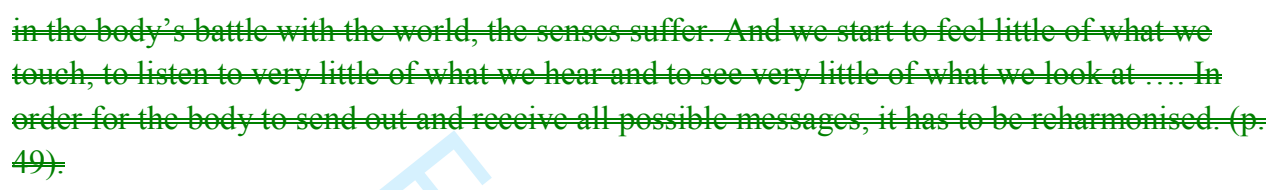

\section{Context 1: Author 2's work with 'Games of Presence'}

Indigenous methodologies have emergedarrived as a particular approach to research that is based upon Indigenous holistic knowledge systems (Rigney 1999; Wilson, 22001). "Given the respect for varied forms of knowledge legitimized within Indigenous ways of knowing, it follows that embodied experience is integral to what we know and how we know it. Embodied | knowledges live within the body and are expressed through it” (Ritenburg et al,2 2014,p. 70). David Abram (1996) states: "Communicative meaning is always, in its depths, affective; it remains rooted in the sensual dimension of experience, born of the body's native capacity to resonate with other bodies" (pp. 74-75). Indigenous researchers and their allies have recognized such dimensions of knowing and have invited such embodied knowledge into discussions of holistic knowledges.

This article draws from research project Name of Project where Author 2. Using a wide variety of arts programming,the research project tame of Project Aur 2 was a co-principal investigator.part Using a wide variety of arts programming, the research investigatedef an investigation over ten years of how theatre and other applied arts contribute to the holistic wellbeing in Indigenous youth from 12 to 25 years old.

Our program processes were the medium, subject, and representation of collaborative play and had an holistic foeus, combining research with education and health. The arts were used to 
develop participants' relationships in the physical, intellectual, social/emotional, and spiritual domains, in accordance with an Indigenous holistic view of health. We adapted "Theatre of the | Oppressed" (Boal, 1979, Diamond, 22 2007, Rohd, 1998) workshops for (Canadian) Indigenous youth, using theatre games (Boal, 1992) and other activities to create a space for youth to explore how the choices they make affect their wellbeing, such as peer pressure and drug and alcohol abuse, and to create imaginative "blueprints" for possible future choices.

In all our programming, "Games of Presence" (Gee 2015) which refers to activities usually | categorized as warm-ups, energizers, and exercises in applied theatre programs, were used to engage youth and develop positive relationships, creative thinking, and self-determined action. Youth report that engagement in games of presence enhances their feelings of wellbeing, helps them overcome shyness, and boostsdevelops their confidence while building positive relationships with others (XXXX 2011; XXX 2013; XXXXX, in press). We saw games of presence as one way to invite play into holistic learning, wellness, and cultural identity. The youth participants in our workshops have told us that these games are not just fun - they have a greater significance-in that they have enabled repair of fractured peer relationships.

While developing an approach that uses applied theatre as decolonizing practice, it has become essential that we also understand the history of Indigenous people and the creation of the colonial state of Canada. Of particular relevance to our research into applied theatre with Indigenous youth is the work of Cherokee Theatre of the Oppressed facilitator Quo-Li Driskill. To Driskill (2008), colonization is an act "done to bodies and felt by other bodies .... [that is] damage done to our skin, flesh, muscles, bones and spirits." (p. 155). Colonization imposed a set of beliefs and moulded the body "through direct behavioural influences and physical environments" (Fay, 1987, p. 144) such as confinement to reserves and confinement in residential schools. Indigenous knowledge identifies a local system of being, knowing, and expressing inculcated into all aspects of a society's knowledges, language, and practices (Settee; $z \underline{2} 013)$.

It follows then that decolonization requires healing through a kinaesthetic process that is central to applied theatre practice. Decolonization is about self-determined action, but agency is also dependent on having a well-developed imagination.

Decolonization requires action centralizing traditional Indigenous knowledge to reclaim equitable ways of interacting to co-create new possibilities, transforming political and personal histories. Boal (1992) notes "a bodily movement is a thought and a thought expresses itself in a corporeal form" (p. 61). If we challenge the youth it is to challenge the youths' ways of being that is a result of a colonial imposition of a certain identity that also imposes colonial relationships on their interactions with others. SoW we work reflexively through our bodies, where we are aware of cognitive processes that emerge in physicality. For example, we often hear the phrase "I could feel something is wrong"; knowing is embodied and is evident as a physical feeling. Our bodies process the experiences (emotions, thoughts, feelings) we have 
Theatre games are creative and playful opportunities that lead to collaboration and embodiment | that engages the body, mind and spirit (Kangas, 22010). These are both games with specific rules and endpoints (finite games) and games with rules that change in the playing of the games (infinite games) and have no definite ending (Carse 1987). As Marjanovic-Shane (2010) underlines, 'participants in play are seen as the collaborators in creating and directing their relationships, judgements, values and even rules' (p. 43).SotThe choice of games is therefore often dependent on the interplay between facilitator experience with using the games in other workshops with similar participants, the 'material' of what happens in the games and the purpose of the games themselves. Ellen Schön (1998), a potter and the daughter of Donald Schön writes, "I try to push myself to be open to the reflective process in order to be more responsive to what the material/situation is telling me so that I don't impose my tools and ideas on the material in a mismatched way. (n.p.)" Thus the artistic process involves a simultaneous process of making (I do) while also reflecting on that intuitive making in the process of developing form (I observe). The resulting form is often the only evidence of the intuitive understandings that occur during the development process. Implied in those interpretations are my judgment and standards as to what has worked or not, and choosing processes for the next stage.

We don't think about what we want to do, but, rather, experience the situation and that experience draws our 'doing' out. Those experiences build up one upon the other and we draw on them the next time a similar situation occurs. This is common in artistic creation. The process of "painting is an intimately communicative affair between the painter and (their) painting, a conversation back and forth, the painting telling the painter even as it receives its shape and form (Schön and Rein 1994, p. 167). 
Whatever part of the workshop process we are in, each part of the process informs and is integrated into the other. And other experiences we have had emerge through a similar reciprocal process, full of surprises and accidents (unintentional results to be noticed and made use the next time or not). There may be no clear end point to the process.

Ellen Schön works with clay. A successful form results from an artist such as she being able to "regard the wood or the metal as a living thing with needs and feelings of its own and to let the material direct them as much as they direct it" (Schön 1964, p. 127).

We will use some specificThe best way to illustrate this is to use the theatre games used in our programs that will illustrate as examples of 'living-through' the 4Rs.

\section{Respect}

In many Indigenous communities, the talking circle is a ritual that is used to create a space for self-determined sharing. Our workshops begin in the talking circle with an Elder from the | community speaking. This which sets the tone for the workshop. Participants are asked to respectfully listen to the Elder and to each other as an object such as a stone is passed from one to the other in either, depending on the culture of the community, a clockwise or counterclockwise manner. Each person holds the rock before deciding whether or not they will speak. In the circle, we connect ourselves to our life experiences and to the workshop community, acknowledging both our personal histories and the present moment. This sharing, even if it is only one word, createsdevelops an atmosphere of ritual and community ${ }_{2}$ and respect for each other and the others' gifts that they bring to the circle. There are no interruptions or cross talk as all participants in the circle are encouraged to share or pass and to listen to each other.

We emphasize that what is said in the circle remains in the circle. This acknowledges and values the cultural protocols present in Indigenous communities and links the youth to their heritage, spirituality and language, while bringing-and brings those links into the workshop space. We do this at the beginning and end of each day and sometimes when we debrief an activity or need to calm the group. As adults we model sharing in the circle because often, initially, youth are reluctant to share. We emphasize with the youth and ourselves that this ritual is not a prelude to, but an integral part of, our practice of working respectfully together, of being present in the particular space, and in developing healthy relationships. While the context might differ in a university classroom, we feel it is important to have some sort of ritual that sets the tone in an embodied way. 
An activity that we often use early on in a workshop is Colombian Hypnosis (Boal 1992). This game, played in pairs, creates an opportunity for participants to connect with one another oneon-one in a waythat was different from their day-to-day interactions, and to practice in power and trust (Johnston 1998, 120). In pairs, the leader movesd their hands in front of their partner's face and the partner followsed as they are led around the room in various positions dictated by the leader. By following another person, participants are requiredwere impelled to adopt postures that may have been unusual to them, breaking from comfortable patterns, and using their bodies in new ways. This brought the focus to the body and emotions, and opened participants to new ways of being. Then each follower becomes a leader and the leader becomes a follower. The leader has to pay attention to the possibilities and limitations of their following partner. Since each person gets to try out being both leader and follower, they become aware of their responsibility as a leader and as a follower.

Then, after a period of time, we ask them to work together: both lead and both follow. Generally, participants are confused by this direction and stop, then each puts a hand in front of the other's face. But when we state that you aren't changing your role (ie. the hand is still in front of the follower's face and the face follows the hand) we would like both lead and follow, this seems to transform things. How does one work in a relationship of respect now? How is power a collaborative force? In debriefing this activity, we ask whether participants preferred | being a leader or follower and why, and how notions of the power residing in the leader links to the idea of being responsible for someone else and their movement. Participants who prefer | being a follower comment on being responsible for themselves instead of nend nust 'going along' when a risky movement is required by the leader. A sense of resistance by either leader or follower is also commented on.

\section{Relevance}

In one activity known as Pass the movement participants are challenged to accept other participants' reality, adapt to one another and transform it to their own reality, thus learning to co-operate with others. In this game, the group standseod in a circle with one member starting a movement with an associated sound. The others repeatsed the movement until another participant spontaneously takeseok the place of the person at the center and adaptsed their pattern. Through this evolution of shape and sound, a transformative process begians.

Later on we introduce the idea of communicating without words through Image Theatre. Based on the idea that "a picture is worth a thousand words" (Jackson, 1992, p. xx), Image Theatre enables participants to create collectively, with their bodies, static images to tell their stories. Alternative ways to change relationships are discussed through a process between facilitators and participants, thus enabling new information to emerge. This process leads to reflection that produces other images. 

given a creative goal that was culturally responsive to their community, participants are able to clearly express themselves through their images. Done initially in pairs, where one is the sculptor and the other their 'clay', each participant has a chance to create a visual representation of what a word or prompt means to them, the stories in a static image drawing from the participants' own experiences, chosen by them, given bodily expression.

\section{Responsibility}

Inside this word is the stem 'response. Balancing is a good activity to experience both the stem of 'response' inside this term and the act of 'responsibility'. To instill trust and openness, participants are invited to pair up with another participant for a balancing exercise where they learned to find the balance of strength between the two of them. The instructions are for each of | the partners to push. The one who is stronger pushes less hard, the one who is not as strong pushes harder. Find the balance of strength - without talking. Have a conversation with your bodies. The exercise can go from pushing on hands to shoulders to fingers to backs, etc. Now try this in groups of 4,8 , etc. There are many variations of this.

| NextThen move to pulling the other by taking each other's wrists; lean out, take each other's weight; without talking, continuing to lean out, sit down. Now, pulling against each other, stand up. Now try this in groups of 4,8 , etc. There are many variations of this. This is a cooperative activity.)

A second activity, normally used as a collective warmup, is Circle Dash. In this energetic activity, participants and facilitators_stand_in_a_circle,_with_one_person_in the middle. They_are instructed_to_switch spots with someone by using non-verbal communication- usually done when assent through eye contact is made. There should be an acknowledgement that both parties agree to move. With this rule in mind, if there is no agreement and someone moves, then | the person who moved into the circle without the other person's agreement; must now be in the middle. The notion of making and acting on a decision that involves someone else emphasizes the idea of responsibility in an embodied, moving way. The whole group becomes a living, complex system as people are exchanging places rapidly. One action leads to another and another.

\section{Reciprocity}

Co-determination is a concept in English reflective of the Nehinuw (Cree) relational concepts of weechiseechigemitowin (alliances for common action) as well as weechiyauguneetowin (partnerships) first used in a presentation by Cree scholar Keith Goulet (2003) to apply in educational contexts and elaborated in Goulet and Goulet 2014. 
This is illustrated and embodied by the Mirror Exercise. Partners are lined up opposite one another a couple of feet apart. First of all, on direction from the facilitator, Line A leads and Line B follows. Then, after a couple of minutes, Line B leads and Line A follows. Lastly, the direction is made that without any pause, Line B and Line A both lead and both follow. Once we sense all the pairs have begun to find a common rhythm and movement we go to each pair one by one and ask them to keep their rhythm and movement but join another pair next to them, so there are groups of 4 following and leading each other and finding a common movement. Once all the groups of 4 are formed we may suggest (depending on a sense of synchronisation in the group) that groups start moving around the room and finding groups to work with or break off to join other group's rhythms and movement. At times we see the whole group find a common rhythm.

This activity both complicates the interpersonal activity of Hypnosis, allows the entire group to find a sense of reciprocity through the building of relationships through embodied movement and enables the facilitator to experience a sensation of reciprocity between leader and group.

\section{Relationality: Putting the 4Rs all together}

Participants succeeded in building trust in one another as a sense of safety and supportiveness developed amongst the group (Johnston 1998, 132-133). The Knots game is one of negotiation which requires participants to observe and connect emotionally and empathetically with one another's needs. In Knots, people stand in a circle, shoulder to shoulder. They then extend their right arms and find someone to connect hands with. They then take their left hands and find another hand that is neither next to them or the same hand they grabbed with the right hand. Now that the group has made a knot, they have to find a way out of the knot without letting go of any hands.

In all cases, a processing of the activities, relationship and self (PARS) is used to debrief the games. PARS (Glass and Benshoff 1999) separates the processing of an activity to talk about the games in terms of activity (what did we do and how?) on self (how did it affect me), relationships (how did the group work together; how did it create new sorts of relationships or not?) and in terms of applying it to work in whatever context the workshop is working with, that is,. as theatre facilitators, as community workers, as organizational development consultants. In all cases, the processing can also happen through another activity. For example, Author 2 has engaged in the mirroring activity and then asking the groups that are being formed 
to make an Image of the moment when 'reciprocity occurred'. We then discuss the images presented in terms of what qualities are unearthed through the visual language of bodies in relationships. This furthers our understanding of what reciprocity, or whatever prompt that has been used, looks like and how we might apply this in our work with groups and communities.

\section{Engaging knowing through telling}

Marlene Brant Castellano (2000) identifies that knowledge is also intuitive and orally transmitted. Scholarship within Indigenous education has been useful in the inclusive nature of what we understand as Indigenous knowing. The role of myth, story and spirit are also important (Cajete,2_2004).

Stories can act as mirrors to life, offer opportunities to vision and dream and provide answers to social questions through metaphorical connection (Kearney,2 2002). As containers, narratives allow for a range of stories to merge in the creation of a communal whole. Like Hutchin's (2014) idea referred to earlier in this paper, of beings creating their own experiences through embodying actions, when we 'story' our experiences, we pass on knowledge and learning to those listening who in turn have an impact on the life of the story. This creates a re-storying of lived moments that is communally created and shared. As each story is told and then re-told, it is shaped and re-created by the connections made with those who have heard it, spoken it, and/or been moved by it. For theatre facilitators and practitioners, each iteration of character adds layers to our understanding of ourselves and we move in and out of a metaxic 'dance', drawing on and adding to a much larger narrative.

\section{Context 2: Author 1's work on 'Storying and Re-Storying'}

As stories offer space - particularly aesthetic and temporal - in which trust can become possible through the communal understanding described above (Simmons, 2 2006), embodying each other's stories becomes a way of generating data about the way we process our work. My Author 1's doctoral research involved exploring a-dramatherapeutic storytelling process known as the 6-Part-Story Method (Lahad 1992) through Image Theatre (Boal,2 2013) with educational professionals who met once a month for two hours with meAuthor 1 , over the period of a year. They-and engaged in embodied storytelling - creating, telling, listening and embodying their own and each other's fictional stories based on their professional lives. The purpose of the research was to examine how an embodied process could aid the experience of 'reflexing' (reflexively processing in action). As with the first context explored earlier, this storying and re-storying process is viewed through the lens of the $4 \mathrm{Rs}$. Additionally, the $5_{\alpha}^{\text {th }} \mathrm{R}$ used by Author 2 of 'relationality' is also employed to connect the learning and to consider the question: where next?

\section{RelevanceRespect and Relevance}


The language of the body is a shared construct where reflective processes experiences are relational and learning are-learning is continual, organic and felt processes-formed by our interactions with the world around us. Unlike verbal or written language, body-language offers multiple layers of meaning and possibility as each individual projects their own meaning into | what they experience. The body is often the conduit for understanding self (Jones, 2_2007). The individual creates new knowledge, not in isolation but instead within a social world that | influences and is influenced by the individual (Fook, 2 2002, 2010). Transformative possibilities therefore exist in the shared experience of having your created story heard and recreated through the actions of others. All stories heard are therefore potentially relevant to an individual's situation, and that relevance can be explored through image work. But in the creating, telling and re-creation of story, lies challenge and uncertainty for the teller and a requirement to trust and be trusted. The process of engaging in this social world is a lived, embodied experience which is subjectively understood by the individual based on the way in which they interact and what histories they bring to that process. In rich and deep reflection, it is often possible to lose yourself in the turmoil that can unfold through the uncovering of selfknowledge. A and respectful hearing of another's story is a vital part of the discovery process.

During Author 1's research process, the participants worked collectively to explore their own professional practice and this required an openness to be vulnerable and to trust the others in the group, including the researcher. As stories are told, a co-creative relationship develops between teller and listener which impacts on the story structure and content based on the listener's influence in the act of exchange (Forest 2009; Lakoff and Johnson 2003). This act of cocreation and sharing requires respectful appreciation for the creator/teller's original story and the relationship between teller and listener becomes a precious thing (Gersie 1997). As participant PC stated:

"You can expose a lot of rawness in somebody. You know, quite powerful.......... think the cards can evoke and do evoke a lot of emotive reactions." (PC):

Narrative, and story creation and telling, are an integral part of the postmodern theories of reflection, critical reflection, reflexivity and embodied reflexive processes. As containers, narratives allow for a range of individual stories to emerge in the creation of a communal whole | (Kearney,22002). As pedagogues of theatre practice, there are times when, intentionally or otherwise, the facilitator becomes emotionally and physically connected to what is created, becoming an almost invisible or 'ghost' participant, while also being holder of the process. In these moments, we learn about our own story and how it connects with others through metaxic moments. Boal coined the term Metaxis which can be defined as the experience of belonging to two worlds simultaneously; the real, physical world and an alternative and fictive reality created by being able to see oneself as both character and actor (Boal, 1995). This is a transitional place where reflective and reflexive stories and narratives emerge, evolving from instant reactions to stimuli around us. 


\section{Responsibility and Reciprocity}

As stories are told, a co-creative relationship develops between teller and listener which effects change in the story structure and content based on the influence of the listener in the act of exchange (Forest, 2 2009; Lakoff and Johnson,2 2003). In this way, the listener shares responsibility for the life of the story and, like_Author 2's' earlier comment on this second ' $R$ ', the word 'response' forms the mainstay of 'responsibility'. Each iteration of narrative brings a new way of viewing the same material and feedback - or response - from the range of listeners the story is told to.

In one session in the research process, this co-creation, and development of meaning for listener and teller, was particularly obvious. One participant (known as PB) created an image of part of her story which involved two central characters; the 'force' and the 'beast'.

PB's image reflected a physical and emotional distance between the 'beast' and the rest of the participants in the image and she explained her rationale for this:

| "At the moment, we're in control. The beast will only be aroused if we chuck something at her or shout or move into her space. We could choose to look at it, move over but basically it's up | to us."

As the session developed, PB returned to the idea of the 'beast', re-contextualising it within a different situation and storyline and indicating that she was intuitively making connections between the significant learning from the previous context (Taylor, Fisher and Dufresne 2002).

| "For me it's about the beast and why would you approach it? My inclination is to walk away whereas some people like to chase it. The characters are wanting [sic] to seek it and tease it or appease it. There are others of us who are thinking let's just leave it."

What is interesting is that all of her fellow participants gained transformational moments of learning from her story, correlating with the argument that knowledge is built through socially | constructed processes of interconnected narratives (Boje,2 2001, 2006; Fook,2 2010). For example, $\mathrm{PD}$, a fellow participant, stated in a later reflective conversation:

| "Aan individual 'aha' moment for me was obviously the one about the monster in the corner, and that was connected to [the story I told]...it's something that had happened in my work and I was thinking I may as well just leave. And it was a person but really she wasn't bothering me so just stay out of the way......that was one of those moments for me when I thought 'just leave | it alone'..-

PC, another participant, also revisited this story in a later reflective discussion, indicating a very strong resonance with his experiences: 
"I actually think it was a massively pivotal bit....and there was a kind of almost revelationary
[sic] 'road to Damascus' transformation for me...."

These moments of shared and physically felt learning, have great significance and highlight the power of theatre to affect considerable change in the aesthetic space between two realities; that of the lived experience and that of the imagined. The discussion about the 'beast' led PB on a journey through experiences in her professional situation at the time and she described how she saw her real situation made manifest in the 'as if' reality:

| "do the job, do the best you can, just get on with it and not look for anything anymore from these beasts. Just do what you do and don't care about the beasts....I misunderstood that until | just tonight.".

\section{Relationality: Weaving Into and Onwards}

Revisiting my own written reflections on the session, I was struck by the very physically felt connections I made between the storied experience of the teller and my fellow journeymen, and myself. I wrote:

I had a physical response to that moment. A 'hairs on the back of your neck' experience, that kind of prickly feeling when someone touches a nerve through what they say. And I think it was the physical expression, seeing them place the 'beast' in the corner and then ignore it, that's what I can do in my own world.

I recall that it was difficult not to join the participants in their storyworld, at this point, but the distance enabled me to reflex in-on-through my actions as facilitator of the process and almost to self-spectate. I also recall that I shared this sense with the participants at the time and we discussed the duality of my position as both actor (researcher/facilitator) and character (learner/co-participant). This was a true metaxic moment being both creator and audience of my own reflexive process, and one which gave me pause to consider how I as the facilitator of this learning process support the pedagogic process for those in the group. Ironically, I believe that this was not my role to fulfil but rather a collaboration between us which moved the knowledge creation process from the one to the many (Boal, 1995; Gersie 1990; Gersie and King; 1997) and allowed for an embodied self-awareness (Leigh and Bailey,2 22013) to emerge.

\section{Concluding thoughts}

One approach to exploring embodied pedagogy would be to site it in the literature and research around embodied cognition. But what happens when we put together the notion of embodied cognition in living systems with a framework around reciprocity and relationships like the 4Rs. We feel it enables a different type of reflection or what Tosey, Visser and Saunders (2012) call diffraction, which involves identifying possibilities that enable challenges to our actions. 
We began this article by asking about how we, as pedagogues using theatre, respond in embodied ways to what happens around us in different contexts. Our explorations here have raised new questionsfor. For example, when thinking of the 4Rs of responsibility, relevance, reciprocity and respect (which come from a Canadian Indigenous context), how are these culturally determined? When workshops with marginalized populations, how do these norms get translated, and how does this translation differ when faced with different populations? When working in schools where students expect certain roles of their teachers, how do these norms challenge the taken-forgranted role of teacher and student? How is the identity of the pedagogue/facilitator a key factor in applying embodied ways of knowing?

We are making the case -these principle of the 4Rs apply to people in theatre workshop contexts since these involve humans and thus are living human systems. Varela et al (1991) make a crucial point that clarifies the idea of a living system:

We do not retain the notion of an independent, pregiven environment but let it fade into the background in favor of so-called intrinsic factors. Instead, we emphasize that the very notion of what an environment is cannot be separated from what the organisms are and what they do." ( $\mathrm{p}$. 198).

The above is a critique of neo-Darwinian evolutionary theory (proposing something called 'natural drift'), butWe are making the case can be made that these principlesisalso applyies to people in theatre workshop contexts since these involve humans and thus are living human systems. Understanding a human system in this way is to sense the space of possibility as being constantly co-enacted and re-enacted in our encounters. Our task as enactors then becomes awaiting $_{2,}$ performing, testing, noticing, listening to "choices" and "options" in embodied interactions that keep the space of possibility alive. As noted earlier, these terms can be summarized as occasioning, which "refers to the way things and events 'fall together' in | complex and unexpected ways" (Davis, Sumara and Luce-Kapler 2000, p. 144). "What is learned is always a complex matter of historical circumstance, immediate context, and anticipated activity" (p. 144). The 4Rs framework comes from a particular historical circumstance. We need to be aware when we engage with participants that those bodies also come from a particular context and history. And so do ours as facilitators/teachers. We need to be aware of the power we have, not just as facilitators, but also as having a certain status based on our perceived identities and the status we are given. We have shared instances where both stories and theatre games require an attunement to the context and the people interacting within it. This sits in the balance between order and chaos. In this in-between is play, which Davis et al define as containing "the possibility of movement" (p. 147), as opposed to seeing knowledge as fixed notions of what learners must learn. 
Similarly, in an effort to use the norms of the 4Rs not as static goals to attain, but as embodied and dynamic, we are always in the process of exploration of what they mean in our practice and reflecting on this process. As-As aa pedagogical process, such embodied reflexivity opens up the possibility for new ways of knowing and understanding. Because it is As-a shared collective experience, embodied reflexive processes become opportunities for complex learning to occur in which participants gain potentially transformational insights into practice through their symbiotic interaction with others. As theatre practitioners and pedagogues, all of our actions revolve around the telling of stories in some form; our own, others'.

Stories are a crucial part of our ability to make connections together and enable us to explore our practice, through moments of vulnerability and trust. Stories created and told represent an individual's past and present experiences, but through the telling, these experiences become shared, evoking emotions, senses and memories in the listener (Coetzee; 2009). Stories can move beyond the descriptive and into that which is not seen, offering more than just a way of knowing. Stories enable reflexive processes to become embodied, felt action and, as such, they stay with us for longer. Mindful of our remit as practitioners, and also the need for a space of safety to be created and held, we have the ability to physically experience as a shared action an individual's idea of the world, and through thise sharing, influence and shape it alongside the participants we work with. As facilitators of corporeal story creation/telling/listening, theatre facilitators and teachers have the opportunity to enable participants to delve deeper into their own experiences in order for both facilitators and participants tote learn from them.

To return to our questions at the start of this paper then; the doing comes from the change of state that occurs when a new experience is lived. In theatre workshops, the physicality of the processes undertaken by both facilitator and participant physically changes the way the body looks, feels and 'is'. As we interact and react to the experiences of others in the group, we are changed and our understanding of the world has therefore moved. How we unpack this is key to developing pedagogical processes to support the participants in their learning. In this unpacking the importance of listening with our bodies to the stories we witness is crucial. This enables participants to feel able to explore their story physically and/or verbally with others in the group, including the facilitator. Also important is how the stories are reflected back and how the facilitator is able to acknowledge their own 'felt' moments linking their experiences to that of the participants. Ultimately, embodied learning is revealed in action (Kinsella-2007) and it is this dynamic that creates opportunities for change.

\footnotetext{
Notes

${ }^{1}$ Chris Argyris and Donald Schön (1974) use the term 'triple loop learning' to distinguish between deepened forms of reflection. This idea in part is based on Gregory Bateson's (2000) notions of 'levels of learning'. Also see Tosey, Visser and Saunders (2012).
} 
${ }^{4}$ We acknowledge the work of the Co-PI $1-1$, who suddenly passed into the spirit world in 2016 and Co-PI 2, who reviewed this article and gave permission for publication, who were the other Co-Principal Investigators along with Author 2 in the research. This research has received ethics approval from X, Certficate \# and Y, Certificate \# along with ethics approval from the Director of Education of First Nations A and its high school.

${ }^{5}$ As per doctoral programme requirements, ethical clearance was requested from the participants to undertake and publish the research. All participants agreed to this.

\section{References}

Abram, D., 1996. The spell of the sensuous. New York, NY: Vintage Books.

Alvesson, M., C. Hardy and B. Harley., 2008.Reflecting on reflexivity: Reflexive textual practices in organization and management theory. Management Learning. 45 (3), 480-499. doi: 10.1111/j.1467-6486.2007.00765.x

Applebaum, D., 1995. The stop. Albany, USA: State University of New York Press.

Argyris, C.and Schön, D. A. 1974. Theory in practice: Increasing professional effectiveness. San Francisco, CA: Jossey-Bass.

Bateson, G., 1972. Steps to an ecology of mind: Collected essays in anthropology, Psychiatry, Evolution and Epistemology. London: Intertext.

Beirne, M. and S. Knight., 2007. From community theatre to critical management studies: A dramatic contribution to reflective learning? Management Learning 38(5), 591611.doi:10.1177/1350507607083209. 
Boal, A., 1995.The rainbow of desire, Translated by A. Jackson. London, UK: Routledge.

Boal, A., 1992.Games for actors and non-actors, Translated by A. Jackson. London, UK: Routledge.

Boal, A., 1979.Theatre of the oppressed, Translated by C. A. McBride and L. M. McBride. London: Pluto Press.

Boje, D., 2001. Narrative methods for organizational and communication research. London: SAGE Publications.

Boje, D., 2006. Breaking out of narrative's prison: Improper story in storytelling organization. Storytelling, Self, Society: An Interdisciplinary Journal of Storytelling Studies.2 (2). $28-49$.

| Brandon, J. R., 1978. Training at the Waseda Little Theatre._The Drama Review, 22 (4), December, 29-42.

| Brant Castellano, M., 2000._Updating Aboriginal traditions of knowledge. In G. J. Sefa Dei, B. L. Hall and D. G. Rosenberg, eds., Indigenous knowledges in global contexts: Multiple readings of our world, 21-36. Toronto: University of Toronto Press.

| Cajete, G. 2004. The philosophy of Native science._In A. Waters American Indian thought: Philosophical Essays, 45-57. Hoboken: Wiley-Blackwell.

Carse, J. P.,- 1987. Finite and infinite games New York: Ballantine Books.

Coetzee, M., 2009. (Re)storying the self: Exploring identity through performative enquiry. South African Theatre Journal [online] 23(1). 94-115.

Davis, B., D. J. Sumara and R. Luce-Kapler., 2000.Engaging minds: Learning and teaching in a complex world. Mahwah, NJ: Erlbaum.

Diamond, D., 2007.Theatre for living: The art and science of community-based dialogue. Victoria, BC: Trafford Publishing.

Driskill, Q.-L.., 2008. Theatre as suture: Grassroots performance, decolonization and healing." In: Aboriginal oral traditions: theory, practice, ethics, R. Eigenbrod and R. Hulan. Halifax and Winnipeg: Fernwood Publishing.

| Estey, E., Smylie, J. and Macaulay, A., 2009. Aboriginal knowledge translation._Understanding and respecting the distinct needs of Aboriginal communities in research. http://www.cihrirsc.gc.ca/e/41392.html

Fay, B., 1987. Critical social science: Liberation and its limits. Ithaca, NY: Cornell University Press. 
Fell, L., Russell, D. and Stewart, A. eds., 1994. Seized by agreement, swamped by understanding. Retrieved from http://www.pnc.com.au/ 1fell/book.htm

Finlay, L., 2005., 'Reflexive embodied empathy': A phenomenology of participant-researcher intersubjectivity. The Humanistic Psychologist 33(4), 271-292. doi:10.1207/s15473333thp3304_4.

| Fook, J., and F. Gardner., 2007.Practicing critical reflection: A_resource handbook. London: Open University Press.

Fook. J., 2002.Social work: Critical theory and practice. London: SAGE Publications.

Fook. J., 2010. Beyond reflective practice: Reworking the 'critical' in critical reflection. In: H. Bradbury, N. Frost, S. Kilminster and M Zukas, eds. Beyond_reflective practice: Approaches to professional lifelong learning. Oxon: Routledge, 37-51.

Forest, H., 2009. Artful leadership for creating positive social change: Reflections on an artsBased autoethnography. Storytelling, Self, Society: An Interdisciplinary Journal of Storytelling Studies. 5. 72-89.

Gee, T. 2015. Personal Communication.

Gersie, A., 1997. Reflections on therapeutic storymaking: The usse of stories in groups. London: Jessica Kingsley Publishers.

Gersie, A., and King, N., 1990. Storymaking in education and therapy. London: Jessica Kingsley Publishers.

Glass, J. S. and Benshoff, J. M., 1999. PARS: A processing model for beginning group leaders, The Journal for Specialists in Group Work, 24 (1), 15-26.

Goulet, K., 2003. Aboriginal people and education in Saskatchewan: An overview paper presented at the symposium on international cooperation in Aboriginal/Minority Education, First Nations University of Canada, Saskatoon, SK, August 18.

Goulet, L. and Goulet, K., 2014. Teaching each other: Nehinuw concepts and Indigenous pedagogies. Vancouver: UBC Press.

Halling, S. and Goldfarb, M., 1991. Grounding truth in the body: Therapy and research renewed._The Humanistic Psychologist 19, 313-330.

Hutchins, E., 2014. Enaction, imagination and insight. In: Enaction: Toward a new paradigm for cognitive Science, J. Stewart, O. Gapenne and E. A. Di Paolo, eds. Cambridge, MA: MIT Press. 
Jackson, A. 1992. Translator's Introduction to Boal, A. in Games for actors and non-actors. New York: Routledge.

Jennings, S., 1998.Introduction to dramatherapy: Theatre and healing, Ariadne's ball of thread. London: Jessica Kingsley Publishers.

Jennings, S., 2012.Drama therapy assessment Through embodiment-projection-role. In D. R. Johnson, S. Pendzik and S. Snow, eds. Assessment in dramatherapy. Springfield, IL: Charles C. Thomas Publisher Ltd, 177-196.

Johnston, C., 1998. House of games. New York: Routledge.

Jones, P., 2007. Drama as therapy, theatre as living, 2nd ed. London: Routledge.

Kangas, M., 2010. Creative and playful learning: Learning through game co-creation and games in a playful learning environment. Thinking Skills and Creativity, 5(1), 1-15. doi: $10.1016 /$ j.tsc.2009.11.001

Kearney, R., 2002. On stories: Thinking in action. London: Routledge.

Kinsella, E., 2007. Embodied reflection and the epistemology of reflective practice. Journal of Philosophy of Education, 41(3), 395-409.

Kirkness, V. J. and R. Barnhardt., 1991. First Nations and higher Education: The four R's-| respect, relevance, reciprocity, responsibility. Journal of American Indian Education 30-(3) 1 15.

Lahad. M., 1992. Story-making in assessment method for coping with stress: Six piece story making and BASIC Ph. In S. Jennings, ed. Dramatherapy Theory and Practice 2. New York: Routledge. 192-208.

Lakoff, G., and Johnson, M., 2003.Metaphors we live by. Chicago: The University of Chicago Press.

Leigh, J., and Bailey, R., 2013. Reflection, reflective practice and embodied reflective practice. Body, Movement and Dance in Psychotherapy: An International Journal for Theory, Research and Practice [online] 8 (3). 160-171. doi: 10.1080.17432979.2013.797498.

Lewontin, R.C. 1983. The organism as the subject and object of evolution. Scientia 188, 65-82. Linds, W., 2008. Performing responsibility - Ethical 'know-how' through drama facilitation. Reflective Practice 9 (1), 101-110. doi: 10.1080/14623940701816709

Linds, W., (2006).Metaxis: Dancing (in) the in- between. In: J. Cohen- Cruz and M. Schutzman eds., A Boal companion, 114-124). London, England: Routledge. 
Linds, W., Goulet, L., and Sammel, A., 2013.Dancing together: A conversation about youth and adult relational authority in the context of education. International Journal of Child, Youth and Family Studies 4 (3), 337-356. http://journals.uvic.ca/index.php/ijcyfs/article/view/12432/3768

Linds, W. and Vettraino, E. eds., (2015).Playing in a house of mirrors: Applied theatre as reflective process. Rotterdam: Sense Publishers.

Marjanovic-Shane, A., 2010.Vygotsky and creativity: A cultural-historical approach to play, meaning making, and the arts. New York: Peter Lang Publishing

Maturana, H. R. and F. J. Varela., 1992.The tree of knowledge: The biological roots of human understanding. Boston: Shambhala.

Maturana, H. R., 1987. Everything is said by an observer. In: W. I. Gaia: A way of knowing. Political implications of the new biology, W.I. Thompson, ed. New York: Lindisfarne Press.

Mezirow, J. 1991. Transformative dimensions of adult learning. San Francisco, CA: JosseyBass.

National Aboriginal Health Organization. 2011. Holistic health and traditional knowledge. http://www.naho.ca/blog/2011/07/25/holistic-health-and-traditional-knowledge/

Pippen, J., with Eden, D., 1997.Resonating bodies. Brisbane: QUT Kelvin Grove Campus.

Rigney, L., 1999. Internationalization of an indigenous anticolonial cultural critique of research methodologies: A guide to indigenist research methodology and its principles. WicazoSa Review, 14 (2), 109-121.

Ritenburg, H., Young-Leon, A. E., Linds, W., Nadeau, D. M., Goulet, L. M., Kovach, M. and Marshall, M., 2014.Embodying decolonization: Methodologies and Indigenization. AlterNative: An International Journal of Indigenous Peoples 10 (1), 67-80. doi: $10.1177 / 117718011401000107$

Rohd, M., 1998.Theatre for community, conflict and dialogue: The Hope is Vital training manual Portsmouth, NH: Heinemann.

Schön, D., and M. Rein ((1994). Frame reflection: Toward the resolution of intractable policy controversies. New York: Basic Books.

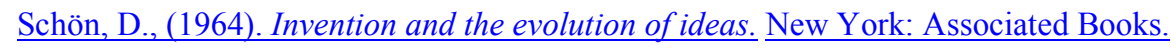

Schön, D., 1983. The reflective practitioner: How professionals think in action. New York:

Basic Books. 
Schön, E. (1998). Online Conference on Donald Schön's Reflective Practitioner.ACTLIST response, 27 March.

Settee, P., 2013.Pimatisiwin: The good life, global Indigenous knowledge systems. Vernon, BC: JCharlton.

Simmons, A., 2006. Building trust several stories high. Storytelling, Self, Society: An Interdisciplinary Journal of Storytelling Studies. 2 (2). 50-67.

Steier, F., 1991.Research and reflexivity. London: SAGE.

Stacey, R. D. and D. Griffin., 2005. Experience and method: A complex responsive processes perspective on research in organizations. In A Complexity Perspective on Researching Organizations: Taking Experience Seriously, R. D. Stacey and D. Griffin, eds. London: Routledge.

Taylor, S., Fisher, D., and Dufresne, R., 2002. The aesthetics of management storytelling: A key to organizational learning. Management Learning [online]. 33, 313-330.

http://mlq.sagepub.com/content/33/3/313/refs.html.

Tosey, P., Visser, M. and Saunders, M. 2012. The origins and conceptualizations of 'tripleloop' learning: A critical review. Management Learning [online]. 43 (3), 291-307. http://mlq.sagepub.com/content/43/3/291

Varela, F. J., E. Thompson and E. Rosch., 1991.The embodied mind: Cognitive science and human experience. Cambridge, MA: MIT Press.

Wilson, S., 2001. What is Indigenous research methodology? Canadian Journal of Native Education, 25 (2), 175-179.

Zarillii, P. ed., 1995. Acting (re) considered: theories and practices.New York, NY: Routledge. 